\title{
Effects of insulin on kidney function and sodium excretion in healthy subjects
}

\author{
P.Skøtt ${ }^{1,2}$, O. Hother-Nielsen ${ }^{1}$, N.E. Bruun ${ }^{2}$, J.Giese ${ }^{2}$, M.D. Nielsen ${ }^{2}$, H. Beck-Nielsen ${ }^{1}$ and H.-H. Parving ${ }^{1}$ \\ ${ }^{1}$ Hvidøre Hospital, Klampenborg, and \\ ${ }^{2}$ Department of Clinical Physiology and Nuclear Medicine, Glostrup University Hospital, Copenhagen, Denmark
}

\begin{abstract}
Summary. Insulin action on kidney function was evaluated in 8 healthy subjects, (mean age 27 years) using the euglycaemic clamp technique. Insulin was infused at rates of 0,20 and $40 \mathrm{mU} \cdot \mathrm{min}^{-1} \cdot \mathrm{m}^{-2}$ over consecutive periods of $120 \mathrm{~min}$ resulting in plasma insulin concentrations of $8 \pm 2,29 \pm 7$ and $66 \pm 14 \mathrm{mU} / 1$. The renal clearance of ${ }^{51} \mathrm{Cr}$-EDTA, lithium, sodium and potassium was determined during the last $90 \mathrm{~min}$ of each period. Sodium clearance declined with increasing plas$\mathrm{ma}$ insulin concentrations $(1.3 \pm 0.4,1.0 \pm 0.3$ and $0.5 \pm$ $0.2 \mathrm{ml} \cdot \mathrm{min}^{-1} \cdot 1.73 \mathrm{~m}^{-2}, p<0.001$ ), while glomerular filtration rate $\left(108 \pm 21,104 \pm 21\right.$ and $108 \pm 20 \mathrm{ml} \cdot \min ^{-1}$. $1.73 \mathrm{~m}^{-2}$ ) and lithium clearance (a marker of fluid flow rate from the proximal tubules) $29 \pm 5,29 \pm 4$ and $30 \pm 4 \mathrm{ml}$.
\end{abstract}

$\min ^{-1} \cdot 1.73 \mathrm{~m}^{-2}$ ) remained unchanged. Calculated proximal tubular reabsorption of sodium and water was unchanged, while calculated distal fractional sodium reabsorption increased $(95.5 \pm 1.5,96.4 \pm 1.2$ and $98.1 \pm 0.7 \%, p<0.001)$. Potassium clearance and plasma potassium concentration declined, whereas plasma aldosterone and plasma renin concentrations were unchanged. In conclusion, elevation of plasma insulin concentration within the physiological range has a marked antinatriuretic action. This effect is located distally to the proximal renal tubules.

Key words: lithium clearance, glomerular filtration rate, sodium excretion, insulin, normal subjects, distal renal tubules.
The role of insulin in sodium metabolism has attracted interest in the light of the increased exchangeable sodium observed in patients with diabetes mellitus [1-3] and the association between hyperinsulinaemia, hypertension, obesity and Type 2 (non-insulin-dependent) diabetes mellitus $[4,5]$.

The effect of insulin on sodium excretion remains controversial. In a classic study, DeFronzo et al. [6] demonstrated that iv infusion of insulin resulting in a mean plasma insulin concentration of $149 \mathrm{mU} / 1$ markedly reduced urinary sodium excretion in sodiumloaded healthy subjects. However, other authors have found no evidence for a significant antinatriuretic effect of insulin [3].

The renal tubular site of insulin action on sodium excretion is also controversial. DeFronzo et al. reported that insulin tended to depress proximal tubular reabsorption of water and sodium, while it enhanced distal tubular sodium reabsorption [7]. In contrast, insulin stimulates proximal tubular reabsorption of phosphate and phosphate clearance has been used as an index of distal delivery of sodium and fluid $[7,8]$. In a recent in vitro study Baum [9] reported that insulin stimulates fluid reabsorption in isolated proximal tubules.

The aim of the present study was to evaluate the existence of a dose-effect relationship between changes of plasma insulin concentration within the physiological range with respect to renal function and sodium excretion in normal man using the lithium clearance methodology as a means of non-invasive functional dissection of the nephron.

\section{Subjects and methods}

\section{Subjects}

Eight healthy subjects ( 4 female, 4 male) mean age 27 years (range $22-32$ years) were investigated. They were all normotensive and taking no medication. Mean body mass index was $22.7 \mathrm{~kg} / \mathrm{m}^{2}$ (range $18.9-25.8 \mathrm{~kg} / \mathrm{m}^{2}$ ). All subjects took their usual diet. The subjects agreed to participate in the study after receiving oral and written information. The procedure was performed according to the principles of the Helsinki Declaration, and the study was approved by the regional ethical committee. 
Table 1. Effects of insulin infusion on kidney function, serum electrolytes, plasma renin and aldosterone concentrations in 8 healthy volunteers

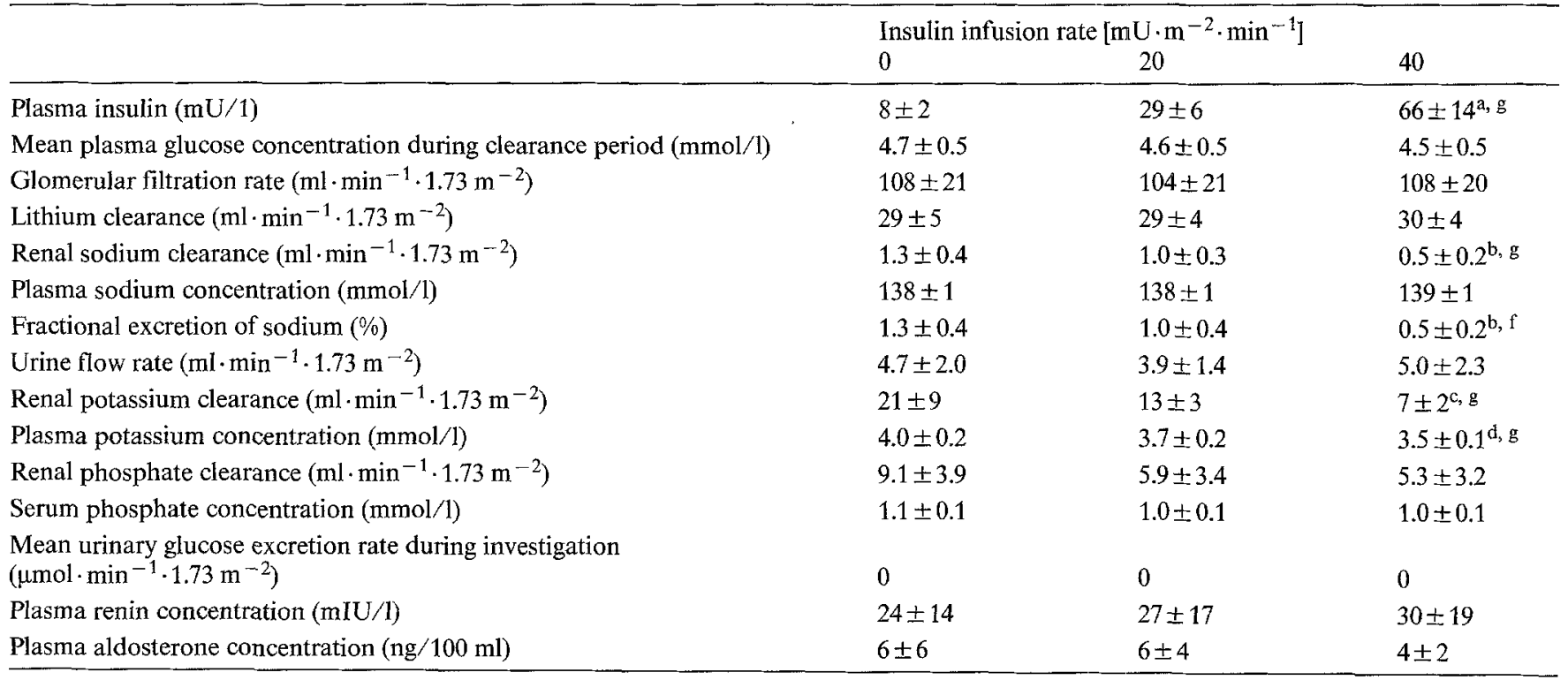

Mean \pm SD indicated.

${ }^{\mathrm{a}}: p<0.000005,{ }^{\mathrm{b}}: p<0.005,{ }^{\mathrm{c}}: p<0.0001,{ }^{\mathrm{d}}: p<0.0005,{ }^{\mathrm{e}}: p<0.00005$, by Friedman test. ${ }^{\mathrm{f}}: p<0.01$ and ${ }^{\mathrm{g}}: p<0.001$ by Page test

\section{Methods}

The subjects received $600 \mathrm{mg}(16.2 \mathrm{mmol})$ of lithium carbonate (DAK Laboratory, Copenhagen, Denmark) orally the evening before the clearance study. The subjects fasted from midnight until the end of the study. During the clearance studies all the subjects were in the supine position, except when voiding urine. The subjects drank $300 \mathrm{ml}$ of tap water per $\mathrm{h}$ beginning $1 \mathrm{~h}$ before the start of the first clearance period.

During the investigation, each subject kept one hand in a heated plexiglas box to enable arterialized venous blood to be obtained. Blood glucose concentration was monitored in arterialized blood with a continuous glucose analyser (Biostator CGIIS, Life Science Instruments, Miles Laboratories, Elkhart, Ind, USA) connected to a forearm vein. Arterialized blood samples were drawn from a plastic catheter placed in another forearm vein on the same arm. $20 \%$ glucose and insulin (Insulin Actrapid, Novo, Bagsværd, Denmark) $100 \mathrm{U} / 1$ dissolved in $\mathrm{NaCl} 154 \mathrm{mmol} / \mathrm{l}$ in water was infused through an antecubital vein in the contralateral arm.

The renal clearance of ${ }^{51} \mathrm{Cr}$-EDTA, lithium, phosphate, potassium and sodium was measured over a basal period of $90 \mathrm{~min}$ beginning 30 min after iv injection of $7.4 \mathrm{MBq}{ }^{51} \mathrm{Cr}$-EDTA (Hoechst, Frankfurt am Main, FRG). At the end of the basal period, an insulin infusion was started at a rate of $20 \mathrm{mU} \cdot \mathrm{min}^{-1} \cdot \mathrm{m}^{-2}$. Blood glucose concentration was clamped at the mean fasting value obtained in the basal period with a variable glucose infusion via the Biostator CGIIS. After an equilibration period of $30 \mathrm{~min}$ the renal clearance measurements were repeated over a $90 \mathrm{~min}$ clearance period. The steady state glucose infusion rate during the last $30 \mathrm{~min}$ of this period was $149 \pm$ $89 \mathrm{mg} \cdot \min ^{-1} \cdot \mathrm{m}^{-2}$. The insulin infusion rate was then increased to $40 \mathrm{mU} \cdot \mathrm{min}^{-1} \cdot \mathrm{m}^{-2}$ and the clearance measurements repeated in a new $90 \mathrm{~min}$ clearance period preceded by an equilibration period of $30 \mathrm{~min}$. The steady state glucose infusion rate during this period was $418 \pm 81 \mathrm{mg} \cdot \mathrm{min}^{-1} \cdot \mathrm{m}^{-2}$. Residual urine was determined by measuring radioactivity from ${ }^{51} \mathrm{Cr}$-EDTA in the pubic region before and after each voiding. After correction for background radioactivity determined over the chest, residual urine was calculated [10]. The clearance values obtained were corrected if calculated residual urine exceeded $20 \mathrm{ml}$.

Plasma glucose concentration was measured approximately every $30 \mathrm{~min}$ throughout the investigation and the continuous glucose ana- lyser adjusted accordingly. Blood samples for plasma insulin measurements were obtained every $30 \mathrm{~min}$ during each of the clearance periods.

Blood samples for measurements of various substances were timed as follows. ${ }^{51} \mathrm{Cr}$-EDTA: every $30 \mathrm{~min}$ during the basal period and every $45 \mathrm{~min}$ during the two following clearance periods. $\mathrm{Li}$ thium, sodium and potassium: at the beginning and end of each clearance period. Phosphate: in the middle of each clearance period. Renin, aldosterone and haematocrit: at the end of each clearance period.

Calculations: The renal clearance of ${ }^{51} \mathrm{Cr}$-EDTA, lithium $\left(\mathrm{C}_{\mathrm{Li}}\right)$, phosphate, potassium and sodium was calculated as the ratio between the urinary excretion rate and the mean plasma concentration during the 90 min clearance periods. For ${ }^{51} \mathrm{Cr}$-EDTA and lithium, the plasma concentration was calculated as the mean interpolated plasma concentration [11].

The absolute proximal tubular reabsorption rate of water was calculated as (glomerular filtration rate (GFR) $-\mathrm{C}_{\mathrm{L} i}$ ), and the absolute proximal reabsorption rate of sodium as plasma sodium concentration multiplied by the absolute proximal reabsorption of water. The fractional reabsorption of sodium and water in the proximal tubules was determined as $1-\left(\mathrm{C}_{\mathrm{Li}} / \mathrm{GFR}\right)$. The absolute distal reabsorption rate of water was calculated as $\mathrm{C}_{\mathrm{Li}}$ - urine flow and the fractional distal water reabsorption was calculated as 1 - urine flow $/ \mathrm{C}_{\mathrm{Li}}$. The absolute distal reabsorption rate of sodium was calculated as plasma sodium concentration multiplied by the difference between $C_{L i}$ and sodium clearance, and the fractional distal sodium reabsorption was determined as 1 - sodium clearance $/ \mathrm{C}_{\mathrm{Li}}$.

Analyses: Urine and serum concentrations of lithium were determined by atomic absorption spectrophotometry (Perkin Elmer 1100 B, Norwalk, Conn, USA) as described by Amdisen [12]. Urine and plasma concentrations of sodium and potassium were determined by routine flame emission spectrophotometry. Urine and serum concentrations of phosphate were determined by standard laboratory methods. Plasma glucose concentration was measured with an automated glucose oxidase method (Glucose Analyser 2, Beckman Instruments, Fullerton Calif, USA) and urinary glucose concentration by the hexokinase method [13]. Haematocrit was measured using a microcentrifuge.

Plasma insulin, plasma renin and plasma aldosterone concentrations were measured by radioimmunoassay [14-16]. 
Table 2. Effects of insulin infusion on calculated segmental renal tubular reabsorption in 8 healthy volunteers

\begin{tabular}{|c|c|c|c|}
\hline & \multicolumn{3}{|c|}{ Insulin infusion rate $\left[\mathrm{mU} \cdot \mathrm{m}^{-2} \cdot \min ^{-1}\right]$} \\
\hline & 0 & 20 & 40 \\
\hline Absolute proximal reabsorption rate of water $\left(\mathrm{ml} \cdot \mathrm{min}^{-1} \cdot 1.73 \mathrm{~m}^{-2}\right)$ & $78 \pm 17$ & $75 \pm 17$ & $79 \pm 19$ \\
\hline Absolute proximal reabsorption rate of sodium $\left(\mathrm{mmol} \cdot \mathrm{min}^{-1} \cdot 1.73 \mathrm{~m}^{-2}\right)$ & $10.8 \pm 2.4$ & $10.4 \pm 2.4$ & $10.9 \pm 2.7$ \\
\hline Fractional proximal sodium (or water) reabsorption (\%) & $72 \pm 4$ & $72 \pm 3$ & $72 \pm 3$ \\
\hline Absolute distal reabsorption rate of sodium $\left(\mathrm{mmol} \cdot \min ^{-1} \cdot 1.73 \mathrm{~m}^{-2}\right)$ & $3.9 \pm 0.7$ & $3.9 \pm 0.6$ & $4.0 \pm 0.5$ \\
\hline Absolute distal reabsorption rate of water $\left(\mathrm{ml} \cdot \mathrm{min}^{-1} \cdot 1.73 \mathrm{~m}^{-2}\right)$ & $25 \pm 4$ & $25 \pm 4$ & $25 \pm 3$ \\
\hline Fractional distal sodium reabsorption $(\%)$ & $95.5 \pm 1.5$ & $96.4 \pm 1.2$ & $98.1 \pm 0.7^{\mathrm{d}, \mathrm{g}}$ \\
\hline
\end{tabular}

Mean \pm SD indicated.

${ }^{\mathrm{a}}: p<0.000005, \mathrm{~b}: p<0.005,{ }^{\mathrm{c}}: p<0.0001,{ }^{\mathrm{d}}: p<0.0005,{ }^{\mathrm{e}}: p<0.00005$, by Friedman test. ${ }^{\mathrm{f}}: p<0.01$ and $\mathrm{g}: p<0.001$ by Page test

\section{Statisticàl analysis}

The results obtained at each level of insulin infusion rate originate from the same 8 subjects. Therefore, ordinary regression analysis cannot be used to establish whether a significant relationship exists between the changes in insulin infusion rate and the observed changes in the measured and calculated variables.

For exploratory analysis, the Friedman test was used [17]. This non-parametric procedure for paired values with more than two groups tests for the occurrence of at least one group, which differs from the other groups. If the Friedman test was significant, the Page test for trend was applied [18]. This procedure specifically tests the hypothesis, that increasing rates of insulin infusion are accompanied by increasing (or decreasing) values of the parameter in question. By this procedure we take advantage of the strength of a paired design where each subject is investigated during three rates of insulin infusion. Thereby multiple pairwise comparisons between each level of insulin infusion and the other two levels are avoided. A $p$-value of $<0.05$ was considered significant. Data are reported as mean $\pm \mathrm{SD}$.

\section{Results}

Results are shown in Table 1 and 2. Plasma insulin concentrations during each of the clearance periods were stable in all subjects. The mean plasma insulin concentrations over the three clearance periods were $8 \pm 2$, $29 \pm 7$ and $66 \pm 14 \mathrm{mU} / 1$ respectively with a coefficient of variation of $12.3 \%, 20.1 \%$, and $7.8 \%$ respectively. The mean plasma glucose concentration over the three clearance periods did not change. The coefficient of variation for plasma glucose concentrations at each of the rates of insulin infusion was $2.4 \%, 3.0 \%$, and $6.9 \%$ respectively.

Plasma sodium concentration did not change. Haematocrit measured at the end of each clearance period declined slightly $(0.43 \pm 0.03,0.42 \pm 0.04$, $0.41 \pm 0.04, p<0.001)$. Sodium clearance declined in parallel with increasing plasma insulin concentrations, while GFR and the output of water from the straight part of the proximal tubules into the thin descending limb of Henle's loop as estimated by lithium clearance remained unchanged. The coefficient of variation across the three steps of insulin infusion was 5.2\% for GFR and $7.8 \%$ for $\mathrm{C}_{\mathrm{Lj}}$. Consequently the proximal reabsorption rate of sodium and water was unchanged. Fractional distal sodium reabsorption increased signifi- cantly $(p<0.001)$, while distal water reabsorption was unchanged. Calculated distal reabsorption rate of sodium increased slightly but non significantly. Phosphate clearance did not change significantly; although it declined at the lowest rate of insulin infusion, it did not fall further at the highest rate of insulin infusion. Serum phosphate concentrations were unchanged. Potassium clearance and plasma potassium concentrations declined with increasing plasma insulin concentrations $(p<0.001)$. Plasma aldosterone and plasma renin concentrations remained unchanged.

\section{Discussion}

We have shown, that elevation of plasma insulin concentration within the physiological range decreases renal sodium clearance without affecting GFR or lithium clearance. These findings suggest that insulin causes sodium retention by stimulating distal tubular reabsorption of sodium.

Originally DeFronzo et al. [6] demonstrated that elevations of plasma insulin in the pharmacological range (about $149 \mathrm{mU} / 1$ ) markedly reduced urinary sodium excretion in normal subjects, possibly by a distal tubular effect. Others have questioned whether insulin exerts a significant effect on renal sodium excretion within the physiological concentration range [3]. Our study suggests that insulin exerts a marked antinatriuretic effect even at plasma levels observed postprandially in normal man. The phenomenon of natriuresis of fasting and antinatriuresis of refeeding $[19,20]$ may, at least partly, be explained by the present findings.

In the present study, calculated proximal reabsorption of sodium was unchanged, while calculated fractional distal reabsorption of sodium increased significantly during insulin infusion. Since distal tubular reabsorption of sodium is load dependent, fractional distal reabsorption of sodium is probably the best suited parameter for evaluation of changes in the reabsorptive rate of the distal tubules. Absolute distal reabsorption rate of sodium is calculated as plasma sodium concentration multiplied by the difference between $\mathrm{C}_{\mathrm{Li}}$ and sodium clearance. $A s C_{\mathrm{Li}}$ is numerically at least 20 
times the value of sodium clearance, even small spontaneous fluctuations of $\mathrm{C}_{\mathrm{Li}}$ will obscure real changes in distal reabsorption. Therefore, it is inherently difficult to detect changes in absolute distal tubular reabsorption rate of sodium using the present methodology. Consequently, the fact that the increase in calculated absolute distal reabsorption rate of sodium did not attain statistical significance does not imply that no change took place. The lack of change in proximal tubular reabsorption strengthens this conclusion.

Previously, phosphate clearance has been used as an indicator of proximal tubule transport [21]. In the present study we observed a decline in phosphate clearance as also reported by DeFronzo et al. [6], although the decline did not attain statistical significance. In the interpretation of phosphate clearance, it should be noted, that a dissociation between distal delivery of phosphate and distal delivery of fluid has been observed and $5-15 \%$ of the filtered load of phosphate is reabsorbed in the distal tubular system [21, 22]. Furthermore, in the present study, the measured values of phosphate clearance were obviously too low to give a reliable estimate of distal delivery of fluid and sodium from the proximal tubules and in accordance with this, proximal tubular phosphate concentration has been reported as declining along the proximal tubule [23].

Experimental studies on the effects of insulin on segmental renal tubular sodium reabsorption are few and conflicting. DeFronzo et al. [7] reported that insulin depressed proximal tubular reabsorption of sodium and fluid in a micropuncture study in dogs. Recently, Baum reported that insulin enhances proximal tubular reabsorption of fluid in isolated rabbit proximal tubules [9]. Indirect evidence supports the view that insulin exerts its effect on sodium excretion distally to the proximal tubules. Insulin stimulates Na-K-ATPase [24], which is abundant in the distal tubules [25]. An excellent correlation exists between Na-K-ATPase activity and reabsorptive capacity in the distal tubule [26]. Also, the number of insulin-receptors is highest in the thick ascending limb of Henle's loop and along the distal convoluted tubules [27]. The receptors are located at the basolateral aspect of the tubules, accessible from the blood stream.

The present study cannot exclude that the effect of insulin on tubular sodium reabsorption is indirect. However, several possible mediators can be excluded with some confidence by our findings or from previous reports. It could be argued, that the effect of insulin is mediated by a renal haemodynamic effect; however renal haemodynamics are not affected by insulin if euglycaemia is maintained [28]. The activity of the reninangiotensin-aldosterone system was not significantly affected. The study of Rowe et al. [29] is widely cited for showing that hyperinsulinaemia induces a rise in plasma noradrenaline and in blood pressure. However, high insulin infusion rates of 2 and $5 \mathrm{mU} \cdot \mathrm{min}^{-1} \cdot \mathrm{kg}^{-1}$ (corresponding to about 80 and $200 \mathrm{mU} \cdot \mathrm{min}^{-1} \cdot \mathrm{m}^{-2}$ ) were used. In fact, blood pressure was unchanged at the lowest rate of insulin infusion, and the corresponding rise in circulating noradrenaline was only $50 \%$. The increase in noradrenaline induced by upright posture is about 2.5 -fold [30]. Using insulin infusion rates very similar to those used in the present study, Airaksinen et al. [31] could not detect any change in noradrenaline or in blood pressure in 12 healthy subjects. Also, no changes in echocardiographic parameters were observed. The fact that plasma renin did not increase significantly in our study would exclude a marked rise in noradrenaline, since low-dose noradrenaline infusion induces a significant increase in plasma renin, if measured after at least 24 min of infusion [30, 32]. In animal experiments stimulation of the renal nerves sufficient to increase tubular sodium reabsorption is also sufficient to cause an increase in renin secretion [33]. Changes in atrial natriuretic peptide is another possibility, but this would require, that a decline in circulating concentrations leads to significant sodium retention. This remains to be shown. Therefore, a direct effect of insulin on the renal tubules seems more likely.

This notion agrees with a most recent micropuncture study in rats published by Kirchner after the present studies were completed [34]. Using the clamp technique he showed that insulin has a marked stimulatory effect on the loop of Henle reabsorption. No effect of chloride or volume reabsorption in the convoluted part of the proximal tubule or in the distal convoluted tubule was observed.

The validity of the renal lithium clearance as a measure of the output of fluid from the proximal tubules has been established in animals [35, 36]. Plasma glucose concentration was kept constant and normal during the experiments, consequently our results are not influenced by changes in blood glucose or by glucosuria, which are both potential confounding factors $[37,38]$. Current discussion on the validity of lithium clearance as a quantitative estimate of endproximal fluid delivery relates to the increase in $\mathrm{C}_{\mathrm{Li}}$ observed after furosemide. This increase may either solely reflect an effect of furosemide on the proximal tubules or it may suggest that lithium is also reabsorbed for some part in the loop of Henle [39]. The finding that insulin, although stimulating loop of Henle reabsorption [34], did not affect $\mathrm{C}_{\mathrm{Li}}$ in the present study would at least suggest, that no quantitatively important change in reabsorption of lithium occurred in the loop during our experiments.

During the experiment the subjects received only tap water and a glucose infusion necessary to maintain constant blood glucose concentration. Water loading per se may lead to a decline in renal sodium clearance [40]. However, diuresis did not change significantly over the three clearance periods, and several studies have shown a remarkable constancy of renal sodium clearance in healthy fasting recumbent subjects for $6 \mathrm{~h}$ during constant water diuresis. This constancy of sodium 
excretion was observed despite the loss of sodium from blood sampling and renal excretion [e.g. 41-44]. During the induction of water diuresis an initial increase in sodium excretion may occur but it appears from published data, that this response lasts for no more than $1 \mathrm{~h}$ $[45,46]$. In the present experiments, the clearance studies were started $1 \mathrm{~h}$ after the induction of diuresis. Plasma sodium concentration was unchanged throughout the experiment, while haematocrit decreased slightly. The decrease in haematocrit corresponds to the change expected because of blood sampling assuming a constant total blood volume.

Major changes in sodium and lithium clearance can be induced by alterations in sodium intake [47]. During the experiments each subject lost about $200 \mathrm{ml}$ plasma containing $28 \mathrm{mmol}$ sodium from blood sampling. The subjects received about $30 \mathrm{mmol}$ sodium from flushing of catheters after blood sampling and from the insulin infusion. The net sodium loss during the experiments roughly corresponds to the renal excretion. In the light of the above mentioned findings it seems unlikely, that this minor change in sodium balance affected our results to any significant degree.

The plasma concentration and clearance of potassium declined but plasma aldosterone concentration remained unchanged. In this complex situation it is not possible to conclude whether insulin has a direct effect on renal tubular potassium secretion and/or reabsorption or whether the observed changes are secondary to changes in plasma potassium concentration [6]. The Na$\mathrm{K}-\mathrm{Cl}$ cotransport system, which has been demonstrated in the thick ascending limb of the loop of Henle, may be involved [48]. A recent experimental study concludes that hypokalaemia masks a direct stimulatory effect of insulin on renal potassium secretion [49]. The conclusion is however, weakened by an unexplained simultaneous increase in renal sodium excretion during insulin infusion. Further studies are needed to elucidate the effects of insulin or renal tubular potassium handling.

In conclusion, increments of plasma insulin concentration within the physiological range markedly reduce renal sodium excretion in normal man. This antinatriuretic effect of insulin is mediated by a direct effect on the renal tubules distally to the proximal tubules.

The interrelated syndromes of Type 2 diabetes mellitus, obesity and essential hypertension are all characterized by hyperinsulinaemia and decreased sensitivity to the glucose lowering effects of insulin (peripheral insulin resistance) $[2,4,5,50]$. In both Type 2 diabetes and obesity an increased frequency of hypertension has been demonstrated. It is unknown, whether renal sodium excretion is resistant to the antinatriuretic effect of insulin in states characterized by peripheral insulin resistance. The bearing of this question on the pathogenesis of high blood pressure is evident.

Acknowledgement. Laboratory technician Ms. S.S. Nielsen provided careful and expert assistance.

\section{References}

1. Feldt-Rasmussen B, Mathiesen ER, Deckert T, Giese J, Christensen NJ, Bent-Hansen L, Nielsen MD (1987) Central role for sodium in the pathogenesis of blood pressure changes independent of angiotensin, aldosterone and catecholamines in Type 1 (insulin-dependent) diabetes mellitus. Diabetologia 30:610-617

2. O'Hare JA (1988) The enigma of insulin resistance and hypertension. Insulin resistance, blood pressure and the circulation. Am J Med 84: 505-510

3. O'Hare JP, Corrall RJM (1988) De natrio diabeticorum. Increased exchangeable sodium in diabetes. Diabetic Med 5: 22-26

4. Landsberg L (1986) Diet, obesity and hypertension. An hypothesis involving insulin, the sympathetic nervous system, and adaptative thermogenesis. Q J Med 61: 1081-1090

5. Reaven GM, Hoffman BB (1987) A role for insulin in the aetiology and course of hypertension. Lancet II: 435-437

6. DeFronzo RA, Cooke CR, Andres R, Faloona GR, Davis PJ (1975) The effect of insulin on renal handling of sodium, potassium, calcium, and phosphate in man. J Clin Invest 55: 845-855

7. DeFronzo RA, Goldberg M, Agus ZS (1976) The effects of glucose and insulin on renal electrolyte transport. J Clin Invest 58: 83-90

8. Hammerman MR (1985) Interaction of insulin with the renal proximal tubular cell. Am J Physiol 249: F 1-F 11

9. Baum M (1987) Insulin stimulates volume absorption in the rabbit proximal convoluted tubule. J Clin Invest 79: 1104-1109

10. Lindbjerg IF, Brandt NJ (1964) Indirect determination of the volume of residual urine with ${ }^{131}$ I-labelled hippuran. Acta Chir Scand 127: 675-680

11. Holstein-Rathlou N-H, Svendsen UG, Leyssac PP (1982) Proximal and distal tubular reabsorption during isotonic volume expansion in patients with essential hypertension as estimated by means of combined ${ }^{51} \mathrm{Cr}$-labelled EDTA and lithium clearance. Clin Sci 63: 219s-221s

12. Amdisen A (1975) The estimation of lithium in urine. In: Johnson FN (ed) Lithium research and therapy. Academic Press, London, UK, pp 181-195

13. Andersen I, Hannibal S (1983) Analytical and economical optimization of a glucose method with immobilized enzymes. J Automatic Chem 5: 188-192

14. Heding LG (1972) Determination of total serum insulin (IR) in insulin-treated diabetic patients. Diabetologia 8: $260-266$

15. Giese J, Damkjær Nielsen M, Kappelgaard AM (1981) Concentrations of active and inactive renin in human plasma: concepts and methodology. In: Sambhi MP (ed) Heterogeneity of Renin and Renin-substrate. Amsterdam, Elsevier/North Holland, pp 205-213

16. Lund JO, Damkjær Nielsen M, Giese J, Gammelgaard PA, Hasner E, Hesse B, Tønnesen KH (1980) Localization of aldosteroneproducing tumours in primary aldosteronism by adrenal and renal vein catheterization. Acta Med Scand 207: 345-351

17. Siegel S (1956) Nonparametric statistics for the behavioral sciences. McGraw-Hill Kogakuska, Tokyo

18. Hollander M, Wolfe DA (1973) Nonparametric statistical methods. John Wiley, New York, USA

19. DeFronzo RA (1981) The effect of insulin on renal sodium metabolism. A review with clinical implications. Diabetologia 21: 165-171

20. Weinsier RL (1971) Fasting - A review with emphasis on the electrolytes. Am J Med 50: 233-240

21. Wen S-F (1974) Micropuncture studies of phosphate transport in the proximal tubule of the dog. The relationship to sodium reabsorption. J Clin Invest 53: 143-153

22. Mizgala CL, Quamme GA (1985) Renal handling of phosphate. Physiol Rev 65: 431-466

23. Gmaj P, Murer H (1986) Cellular mechanisms of inorganic phosphate transport in kidney. Physiol Rev $66: 36-71$

24. Moore RD (1983) Effects of insulin upon ion transport. Biochim Biophys Acta 737: 1-49

25. Jørgensen PL (1980) Sodium and potassium ion pump in kidney tubules. Physiol Rev 60: 864-917 
26. Madsen KM, Tisher CC (1986) Strucutral-functional relationships along the distal nephron. Am J Physiol 250: F 1-F 15

27. Rabkin R, Ryan MP, Duckworth WC (1984) The renal metabolism of insulin. Diabetologia 27:351-357

28. Christiansen JS, Frandsen M, Parving H-H (1981) The effect of intravenous insulin infusion on kidney function in insulin-dependent diabetes mellitus. Diabetologia 20: 199-204

29. Rowe JW, Young JB, Minaker KL, Stevens AL, Pallotta J, Landsberg $L$ (1981) Effect of insulin and glucose infusions on sympathetic nervous system activity in normal man. Diabetes 30: 219-225

30. Izzo J (1983) Cardiovascular hormonal effects of circulating norepinephrine. Hypertension 5: 787-789

31. Airaksinen J, Lahtela JT, Ikaheimo MJ, Sotiniemi EA, Takkunen JT (1985) Intravenous insulin has no effect on myocardial contractility or heart rate in healthy subjects. Diabetologia 28: 649-652

32. Sternheim W, Dalakos TG, Streeten DHP, Fox L, Speller PJ (1982) Action of L-epinephrine on the renin-aldosterone system and on urinary electrolyte excretion in man. Metabolism 31: 979-984

33. DiBona GF (1985) Neural regulation of renal tubular sodium reabsorption and renin secretion. Fed Proc 44: 2816-2822

34. Kirchner KA (1988) Insulin increases loop segment chloride reabsorption in the euglycemic rat. Am J Physiol 255: F 1206-F 1213

35. Thomsen K, Holstein-Rathlou N-H, Leyssac PP (1981) Comparison of three measures of proximal tubular reabsorption: lithium clearance, occlusion time, and micropuncture. Am J Physiol 241: F 348-F 355

36. Thomsen K (1984) Lithium clearance: A new method for determining proximal and distal tubular reabsorption of sodium and water. Nephron 37: 217-223

37. Skøtt P, Bruun NE, Giese J, Holstein-Rathlou N-H, Leyssac PP (1987) What does lithium clearance measure during osmotic diuresis? Clin Sci 73: 126-127

38. Baines AD, Drangova R, Ho P (1987) $a_{1}$-Adrenergic stimulation of renal $\mathrm{Na}$ reabsorption requires glucose metabolism. Am J Physiol 253: F 810-F 815

39. Atherton JC, Green R, Hughes S, McFall V, Sharples JA, Solomon LR, Wilson L (1987) Lithium clearance in man: effects of dietary salt intake, acute changes in extracellular fluid volume, amiloride and frusemide. Clin Sci 73: 645-651

40. Boer WH, Koomans HA, Dorhout Mees EJ (1988) Renal lithium handling during water loading and subsequent d-DAVP-induced anti-diuresis. Eur J Clin Invest 18: 273-278
41. Anderson J, Struthers A, Christofides N, Bloom S (1986) Atrial natriuretic peptide: an endogenous factor enhancing sodium excretion in man. Clin Sci 70: 327-331

42. Hughes JM, Ragsdale V, Felder RA, Chevalier RL, King B, Carey RM (1988) Diuresis and natriuresis during continuous dopamine1 receptor stimulation. Hypertension 11 [Suppl] I: I-69-I-74

43. Morice A, Pepke-Zaba J, Loysen E, Lapworth R, Ashby M, Higenbottam T, Brown M (1988) Low dose infusion of atrial natriuretic peptide causes salt and water excretion in normal man. Clin Sci 74: 359-363

44. Williams TDM, Walsh KP, Pitts E, Sutton R, Lightman SL (1988) Rebound increase in plasma renin and vasopressin following graded infusions of atrial natriuretic peptide in man. J Endocr Invest $11: 31-35$

45. Velasquez MT, Skelton MM, Cowley AW (1987) Water loading and restriction in essential hypertension. Hypertension 9: 407-414

46. Richards AM, Tonolo G, Montorsi P, Finlayson J, Fraser R, Inglis G, Towrie A, Morton J (1988) Low dose infusions of 26- and 28amino acid human atrial natriuretic peptides in normal man. $\mathrm{J}$ Clin Endocr Met 66: 465-472

47. Solomon LR, Atherton JC, Bobinski H, Green R (1987) Effects of dietary sodium chloride and posture on plasma immunoreactive atrial natriuretic peptide concentrations in man. Clin Sci 72: 201-208

48. Chipperfield AR (1986) The $\left(\mathrm{Na}^{+}-\mathrm{K}^{+}-\mathrm{Cl}^{-}\right)$co-transport system. Clin Sci $71: 465-476$

49. Rossetti L, Klein-Robbenhaar G, Giebisch G, Smith D, DeFronzo $R$ (1987) Effect of insulin on renal potassium metabolism. Am J Physiol 252: F 60-F 64.

50. Ferrannini E, Buzzigoli G, Bonadonna R, Giorico MA, Oleggini M, Graziadei L, Pedrinelli R, Brandi L, Bevilacqua S (1987) Insulin resistance in essential hypertension. N Engl J Med 317: $350-357$

Received: 8 November 1988

and in revised form: 9 June 1989

Dr. P. Skøtt

Hvidere Hospital

Emiliekildevej 1

DK-2930 Klampenborg

Denmark 